\title{
X-ray Microtomography Analysis of the Aluminum Alloy Composite Reinforced by SiC After Friction Stir Processing
}

\author{
Anna Wójcicka, Krzysztof Mroczka, Paweł Kurtyka, Marcin Binkowski, and Zygmunt Wróbel
}

(Submitted September 15, 2013; in revised form April 11, 2014; published online June 20, 2014)

\begin{abstract}
Despite many years of using friction stir processing (FSP), there are many unexplained aspects concerning the processes which appear during FSP: determining the direction of flow and mixing of the materials and the degree of mixing and microstructure fragmentation in specific areas. This paper presents the impact of FSP on the micro- and macrostructure of the composite with hypo-eutectic Si matrix reinforced by $\mathrm{SiC}$ particles. The analysis of the structure of the processed area in FSP in the relation to the microstructure of the base material has been made using $x$-ray microtomography. The results of these studies have been juxtaposed with studies using microscopic methods (light microscopy and SEM). The microtomography images revealed an additional separation on the advancing side and the weld nugget, where on the basis of a 3D reconstruction a layer microstructure on the direction of linear movement of the tool has been demonstrated. The analyses have revealed a limited flow of the material above the weld nugget. The main advantages of the research method applied were the possibility to show the invisible or barely visible elements of the microstructure using standard test methods and the ability to analyze the microstructure changes uninterruptedly in different directions in the volume of the material.
\end{abstract}

Keywords 3D model, aluminum alloys, friction stir processing, SEM, x-ray microtomography

\section{Introduction}

Friction stir welding (FSW) was invented at The Welding Institute of UK in 1991 by Wayne Thomas (Ref 1) as a solidstate join technique, and it was initially applied to aluminum alloys. At present, this technology can be used to combine materials of different chemical composition, properties, and microstructure: such as $\mathrm{Al}-\mathrm{Cu}, \mathrm{Al}-$ steel and 2000 series aluminum alloy with 7000 series (Ref 2).The main difference between traditional welding and FSW is a much lower processing temperature and mixing of the welded materials which can enable attainment of lasting and good quality welds. Therefore, one can avoid problems connected with: the

Anna Wójcicka, Pedagogical University of Cracow, Institute of Technology, Podchorazych 2, 30-084 Cracow, Poland and Department of Biomedical Computer Systems, University of Silesia, Institute of Computer Science,X-ray Microtomography Lab, ul. 75 Pulku Piechoty 1, 41-500 Chorzów; Krzysztof Mroczka and Pawel Kurtyka, Pedagogical University of Cracow, Institute of Technology, Podchorazych 2, 30-084 Cracow, Poland; and Marcin Binkowski and Zygmunt Wróbel, Department of Biomedical Computer Systems, University of Silesia, Institute of Computer Science, X-ray Microtomography Lab, ul. 75 Pulku Piechoty 1, 41-500 Chorzów, Poland. Contact e-mail: awojcicka@ up.krakow.pl. solidification process ( $\operatorname{Ref} 3)$, the structure, the loss of alloying elements, the presence of segregation, porosities, and the dendritic structure. A major importance in the FSW process plays a tool which consists of two parts: a shoulder tool and a pin tool (Ref 2). The tool driven into rotation is inserted into the welded material until the shoulder tool makes contact with the welded material and the pin tool penetrates the material (Fig. 1). The production strain causes an increase in temperature of the material to the temperature of its plasticity, resulting in a material which easily flows plastically. The tool moving on the line of welding causes, through the pin tool, the mixing of the plasticized material of the welded parts and creates the weld.

FSW has been adapted to process the local quantity of the material by plastic deformation and thus induces beneficial changes in the properties of this area-the process is called friction stir processing (FSP) (Ref 4). Due to the movement and the work performed by the FSW tool, the welds structure known as the single weld (one kind of material subjected to welding) and the structure of the areas created as a result of being processed by the FSW tool (FSP process), are almost identical. In the case of welding or processing of aluminum and its alloys, the material close to the tool is heated to a temperature up to about $500-530{ }^{\circ} \mathrm{C}$ while in remote areas but still within the work scope up to about $400-450{ }^{\circ} \mathrm{C}$ (Ref 5-7) which can lead to changes in mechanical properties of the welded materials. However, one of the main advantages of this method is plastic deformation which initiates a series of processes that cause favorable changes in the microstructure, e.g., fragmentation and homogenization. Thus, the application of FSP can be very important in the process of improving the microstructure of metal matrix composites of various types where there is often a problem with the uniform distribution of the strengthening-phase particles, known as the reinforcing 


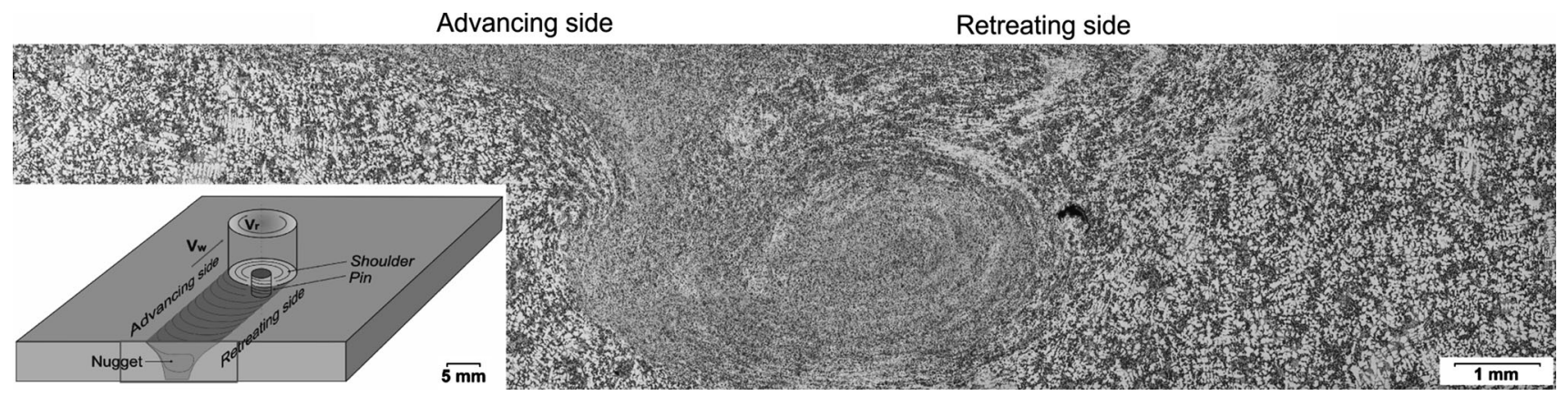

Fig. 1 The macrostructure of transfer cross-section of FSP weld. Panorama made with 21 pictures taken by light microscope. The left side of the picture provides schematic of FSW/FSP process

phase and an appropriate state of precipitates reinforcing the matrix (Ref 3, 8). The dynamic plastic deformation under conditions of severe stress can change the particle size distribution of the reinforced phase and can cause fragmentation by mechanical fragmentation (breaking). The composites of this type are obtained by different methods. The most widely used is in situ and ex situ methods (Ref 9-12). One of them is the method of introducing the reinforcing phase into the liquid material and then casting to form (Ref 11,12$)$. When applying the so-called "gravity casting" method at normal pressure and when the crystallization process is close to equilibrium, segregation of the chemical composition in multi-component alloys appears. In this case, the processing of such material by the FSP method will also apply to the matrix material, causing at least the homogenization of local areas and fragmentation of the grain in the plastically deformed area of the material.

The X-ray microtomography (XMT) was used in microstructure research, as a non-destructive testing method of the internal structure of the object based on the reconstruction of twodimensional x-ray projections recorded at different angles, the result of which was obtaining a three-dimensional image (after reconstruction) (Ref 13). The general principle of the application of X-rays to study the structure has been known since the late nineteenth century (Ref 14) but it was only in the era of advanced machines and computing systems based on advanced computer algorithms when effective and relatively quick processing and analyzing of large amounts of data, including $\mathrm{x}$-ray images became possible. In consequence, progress in this area has led to the creation of a 3D object, with very high resolution (Ref 15,16$)$. Due to its advantages, this technology has been used e.g., in medicine (Ref 17), anthropology (Ref 18) or paleontology (Ref 19). Nowadays, XMT is also used in material science (Ref 20) in the study of micro and macrostructure of objects of different chemical composition and/or containing areas of different density from the surrounding matrix, for example, defects in the form of voids. For this reason, its widest application is observed in the evaluation of the construction of elements obtained by casting methods by applying different casting techniques (Ref 21, 22). Due to the physicochemical and thermodynamic processes of the structure formation of such materials, segregation of the chemical composition and shrinkage (defect) are often observed (Ref 23). Another field of application of the method in material testing is the analysis of different types of joints, seams or welds, in which, due to the specificity of the joining process or features of the joined materials, areas recognizable by XMT may be formed. Not all characteristics of the microstructure mentioned above can be identified by microtomography; nevertheless, a number of information obtained using this method is useful in assessing the characteristics of macro- and microstructure.

This paper presents the impact of FSP on the microstructure of the material after passing the tool through the material. The analysis refers to the microstructure of aluminum alloy matrix composite, reinforced by $\mathrm{SiC}$ phase. The composite obtained by casting shows chemical composition segregation and inequality in the distribution of $\mathrm{SiC}$ particles. The research presented below shows the characteristics of the material in specific areas and enables to assess the suitability of XMT to this type of research.

\section{Experimental}

The material used in the experiment was a composite marked by the manufacturer as F3K.S10 on a base of aluminum alloy matrix reinforced by $\mathrm{SiC}$ particles. The chemical composition of this material was as follows: $9.5 \% \mathrm{Si}, 0.3 \% \mathrm{Fe}$, $2.8 \% \mathrm{Cu}, 0.8 \% \mathrm{Mg}, 1 \% \mathrm{Ni}, 0.2 \% \mathrm{Ti}, 0.003 \%$ others, balance $\mathrm{Al}$, in wt. $\%$. An average size of the reinforced particle is $15 \mu \mathrm{m}$ according to the manufacturer of the alloy.

The material was subjected to FSP process with the following parameters: the rotation rate of $900 \mathrm{rpm}$ and the linear velocity of the tool of $355 \mathrm{~mm} / \mathrm{min}$. The welding process was performed with the use of a conventional tool: a threaded pin with a diameter of $8,3.8 \mathrm{~mm}$ length and a shoulder with a diameter of $18 \mathrm{~mm}$. The FSP was performed at the Institute of Welding in Gliwice, Poland.

The microstructure investigations were conducted with the use of an optical microscope OLYMPUS GX51 with optical instrumentation, software and scanning electron microscope Jeol JSM6610LV with detectors: an upper detector (SEI), backscattering electron detector (BEI) and Oxford's energy dispersive spectrometer (EDS) microprobe and Aztec Software. Microscopic observations were performed on cross-section (perpendicular to the surface of the weld). To create the panorama of the macrostructure of the sample, Microsoft image composite editor (ICE) was used which enabled to constitute a composition of several images of light microscopy. The XMT studies have been performed by laboratory XMT scanner (v|tome $\mid \mathrm{x}$ s, GE Sensing \&Inspection Technologies, Phoenix $\mathrm{x}$-ray, Wunstorf, Germany) using $120 \mathrm{kV}$ voltage, $110 \mu \mathrm{A}$ current, $250 \mathrm{~ms}$ detector timing, and $0.1 \mathrm{~mm} \mathrm{Cu}$ filter. The dataset reconstructed by filtered back projection [Feldkamp method (Ref 24)] consists of $411 \times 380 \times 1010$ isotropic voxel size equal to $16.943 \mu \mathrm{m}$ stored on a single raw file in 8-bits range of gray values (0-255) and was processed by Mimics. 


\section{Results and Discussion}

The microstructure analysis began with microscopic research (light microscopy). Figure 1 shows the macrostructure of a cross-section and provides schematic of the FSP process. The cross-section depicts an area subjected to the process of FSP (central portion), the heat-affected zone (on both sides of the FSP area) and the base material. The macrostructure consists of 21 microscopic images which were taken with the use of a light microscope and made into a panoramic macrostructure by Microsoft ICE. The analysis of the macrostructure of the image obtained shows typical elements for FSW joints, such as the lack of symmetry - a sharp boundary of the area covered by the FSP process on the advancing side and a gently changing microstructure on the retreating side (Ref 25, 26). In the central part, a weld nugget is clearly visible. The location of the advancing and retreating sides, and the nugget in relation to the tool movement is shown in Fig. 1.

In Fig. 1 The differentiated microstructure shows oriented movement of the material during the FSP process with varying degrees of deformation in different areas. In particular, it shows the fragmentation of the microstructure in the weld nugget and in the strip on the advancing side. Dynamic plastic deformation under conditions of high stresses caused mechanical fragmentation of the particles of the reinforcing phase and the eutectic $\mathrm{Si}$. In this case, the plastic processing of such a composite using the FSP method will also refer to the matrix material (Al-alloy), causing its local homogenization and grain refinement in the area of plastic deformation. However, the heat-affected zone and the base material show a structure typical for cast materials (coarse-grained, dendritic structure).

Due to mechanical properties of the composite material, both the state of the matrix, as well as the particle size and distribution of the reinforcing phase (SiC) are of crucial importance. An example of the base material microstructure is shown in Fig. 2, where: 1- SiC, 2-eutectic Si, 3-phase of the chemical composition of Al-Fe-Mn-Si. The precipitation involving Al-Fe-Mn-Si is a result of the presence of iron in the alloy, which is present as an additive alloyed (pollution). Most often these precipitates are $\mathrm{AL}_{15}(\mathrm{FeMn})_{3} \mathrm{Si}$ phase (Ref 27), which are present in commercial aluminum foundry alloys. The

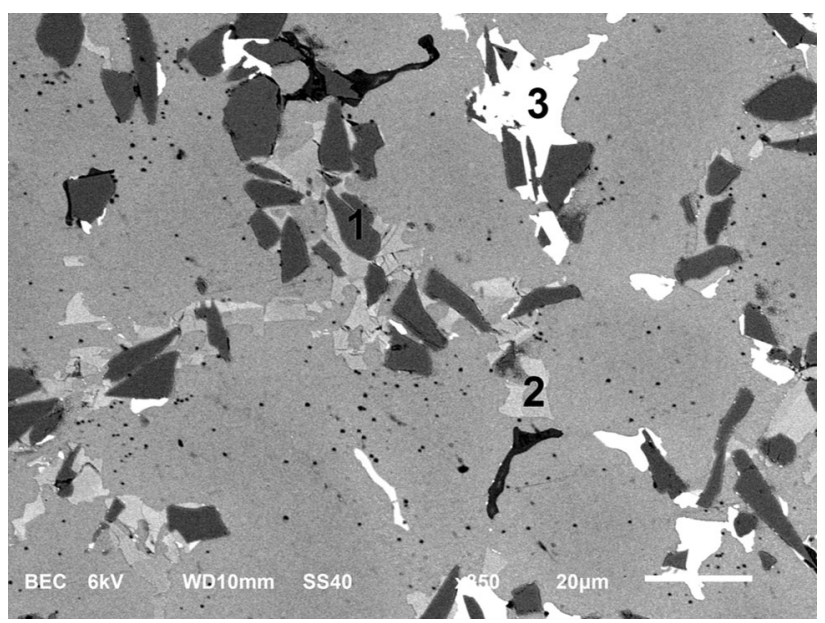

Fig. 2 SEM-BEC microstructure of the base material: $1-\mathrm{SiC}$, 2-hypo-eutectic Si, 3-Al-Fe-Mn-Si above-mentioned phase will be fragmented similarly to the eutectic Si phase.

As shown in Fig. 2, the distribution of particles in the base material is heterogeneous due to the kinetics of the formation of the microstructure in the crystallization process (the material in the cast state). The use of plastic processing, accompanied by multi-directional deformation of the material will radically alter the microstructure, as well as the size and distribution of particles. It is one of the essential features of the microstructure which completes the description of the material structure.

The chemical analysis of the particles was performed with the use of SEM microscopy and microanalysis by EDS method. Based on SEM observations it was also possible to determine the uneven distribution of these particles. Figure 3 a shows the appearance of microstructure of the base material area using BEI detector in BEC mode. This type of observation allows to illustrate areas of different density materials. This method facilitates to differentiate between higher density particles, being displayed as white on a gray background matrix (in this case a phase with $\mathrm{Fe}$ ). The distribution of particles observed results from the formation of the matrix when it is a liquid but below the liquidus temperature. A further analysis of the particle size distribution was made on the basis of chemical composition, SEM-EDS maps (Fig. 3b), based on which it was also possible to establish the location of other phases in the alloy and segregation of elements in the matrix.

The analysis of SEM-EDS maps (Fig. 3b) showed an uneven distribution of $\mathrm{Cu}, \mathrm{Ni}$ and $\mathrm{Mg}$ elements, which are present in the same areas. In particular, the presence of $\mathrm{Cu}$ and $\mathrm{Ni}$ will affect the density increase of the material compared with the aluminum matrix. However, the matrix is not just pure aluminum, but it also contains elements remaining in the solution $(\mathrm{Cu}, \mathrm{Mn}, \mathrm{Si})$ and/or forming precipitates which reinforce the matrix e.g., GP zone or metastable intermediate separation and $\mathrm{Al}_{2} \mathrm{Cu}$ precipitates of small, micrometer size (Ref 25,28 ). The presence of the dissolved elements in the aluminum matrix does not change significantly its density, in relation to the micrometer precipitates above-mentioned. The observations and analyzes made on a single cross-section will enable a better understanding of XMT images relating to the volume of material and/or selected section/profile. These are shown in Fig. 4-6. An example of a two-dimensional projection is shown in Fig. 4 which is part of a complete collection of XMT cross-sectional image dataset.

In Fig. 4 XMT image of a cross-section is shown. In the heat-affected zone and parent material a structure which may remind "cellular structure" can be noticed. The lighter areas show the highest density. The visible "cellular structure" is undoubtedly related to the formation of the microstructure from the liquid state, i.e., the crystallization process. During this process, there was a segregation of components. Precise analysis of the kinetics of this process is difficult because it is a multi-component alloy, and some of areas of a temperature well below the melting point of Al-Si eutectic can be formed. It is especially possible due to the presence of $\mathrm{Cu}$ within the alloy; for example, the eutectic temperature of eutectic $\mathrm{Al}_{2} \mathrm{Cu}$ with $\alpha$-Al is about $507{ }^{\circ} \mathrm{C}(\operatorname{Ref} 29)$. Therefore, it is difficult to assess whether the XMT image shows the cellular structure relates to only segregation along grain boundaries of dendrites $\alpha$-Al, or reveals the segregation of a different range. However, based on the above-mentioned SEM-EDS study (Fig. 3b) study, it can be assumed that the areas shown are rich in $\mathrm{Cu}$ and $\mathrm{Ni}$, which may occur in the form of finely dispersed intermetallic phases. A 


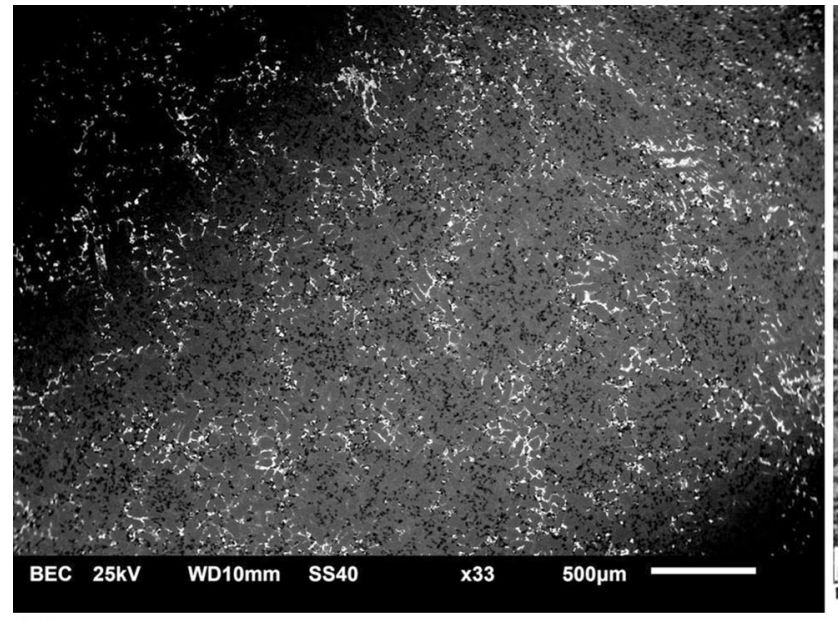

(a)

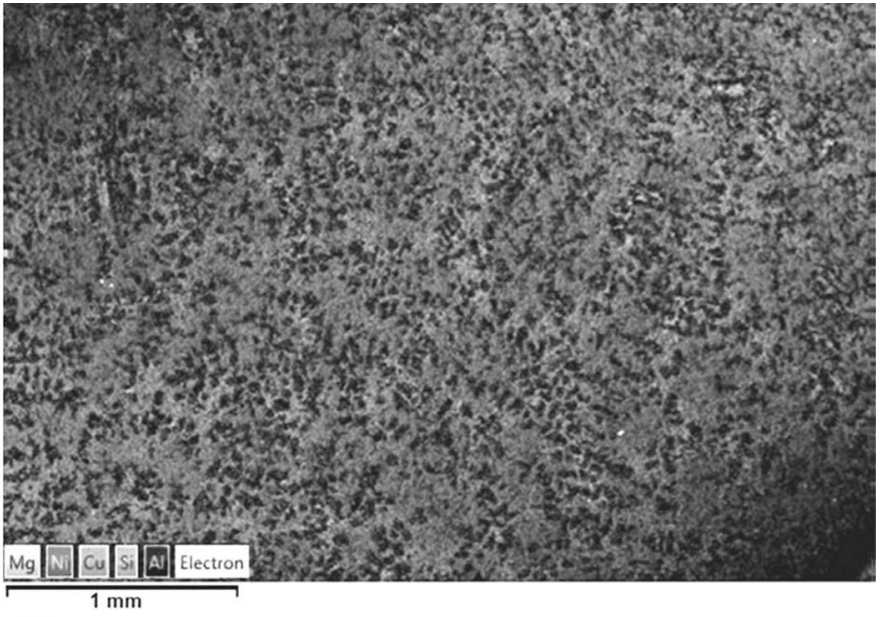

(b)

Fig. 3 (a) SEM-BEC microstructure of the base material (b) SEM-EDS map of the distribution elements

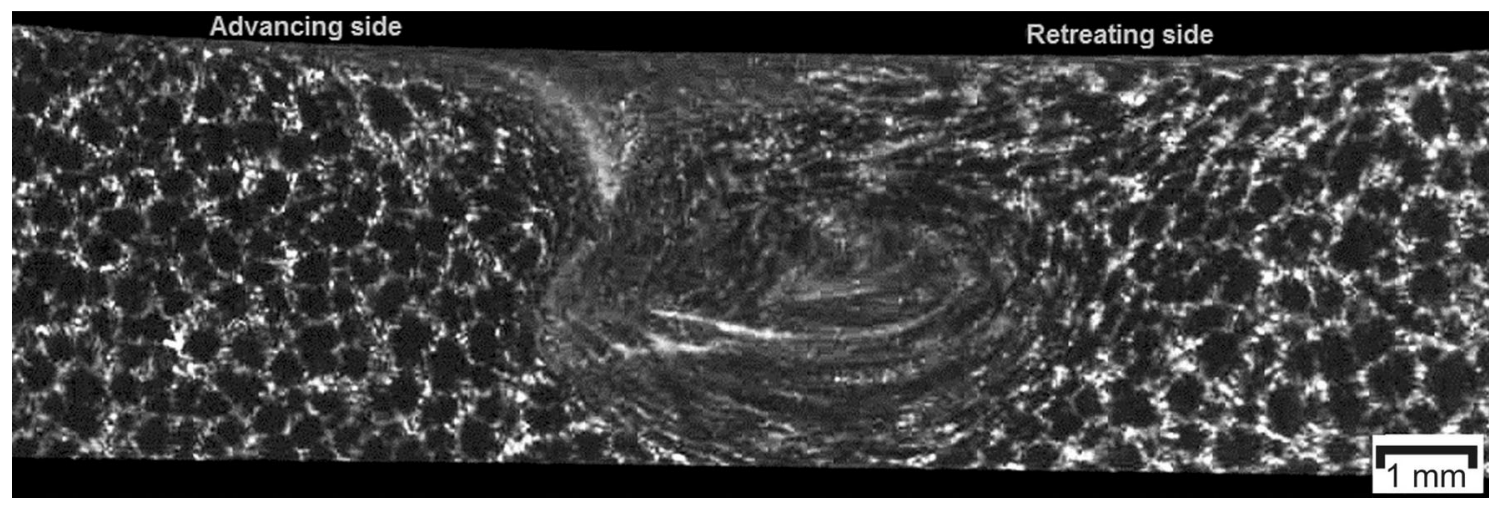

Fig. 4 Two-dimensional cross-sectional XMT image of the composite structure reinforced by SiC after FSP process

darker shade of gray in Fig. 4 indicates a lower density. These areas can be identified as the matrix of the composite-primary Al-rich grains likely. The distribution of reinforcing particles ( $\mathrm{SiC}$ ) and eutectic $\mathrm{Si}$ is not visible on XMT images because of a similar density to the density of the matrix. This means that at this level of observation using XMT only areas with strong segregation of elements with higher atomic numbers are distinguishable. This feature of XMT images and the observation of the parent material have been discussed before (Fig. 4), they can be used to assess changes in the microstructure as a result of the FSP.

As it can be observed, the area transformed by the FSW tool is unsymmetrical and consists of the advancing side, the retreating side and the weld nugget. In comparison with previous observations (Fig. 1), the changes in microstructure caused by the process of FSP are more visible. The advancing side on microtomography images shows differentiation of appearance. A considerable fragmentation of microstructure may be noticed and usually a significant degree of homogenization may be observed which may suggest, however, some lack of homogeneity of the area, which is not visible in Fig. 1.

To obtain more information about the distribution of individual elements and the influence of FSW tools on the microstructure, a segmentation of individual regions of the microstructure was performed.
The result of segmentation is shown in Fig. 5a - the area of the highest density, rich in $\mathrm{Cu}$ and $\mathrm{Ni}$ is shown in white, black and dark gray mark the phase particles containing $\mathrm{SiC}$ and hypo-eutectic $\mathrm{Si}$, while the remaining area has been selected as a matrix composite - an area rich in Al. For a better understanding of the segmentation performed, Fig. 5b shows the original two-dimensional $\mathrm{x}$-ray cross-sectional image.

Figure 6 shows a three-dimensional cross-section model of the weld nugget formed after the reconstruction and segmentation of two-dimensional XMT images, located in the plane of projection in order to improve the location of the site in which it was made. The three-dimensional model significantly expands the scope of the analysis since it reveals changes in the microstructure on the linear motion of the FSW tool, without the need to conduct further destructive samples-cross sections.

The analysis of the microstructure depicted in this manner illustrates a non-uniformity of the area, both in the crosssectional plane, as well as XYZ perpendicular. In the threedimensional model, black area marks conglomerates of phase particles containing $\mathrm{SiC}$ and eutectic $\mathrm{Si}$, and bright gray value refers to the composite matrix. In the applied scale and microtomograph parameters of analysis, it is not possible to identify each particle of reinforced phase. Their size within the area of the pin workplace is between about $1 \mu \mathrm{m}$ (that is, the resolution limit of light microscopy) to $16 \mu \mathrm{m}$. Similar in size 

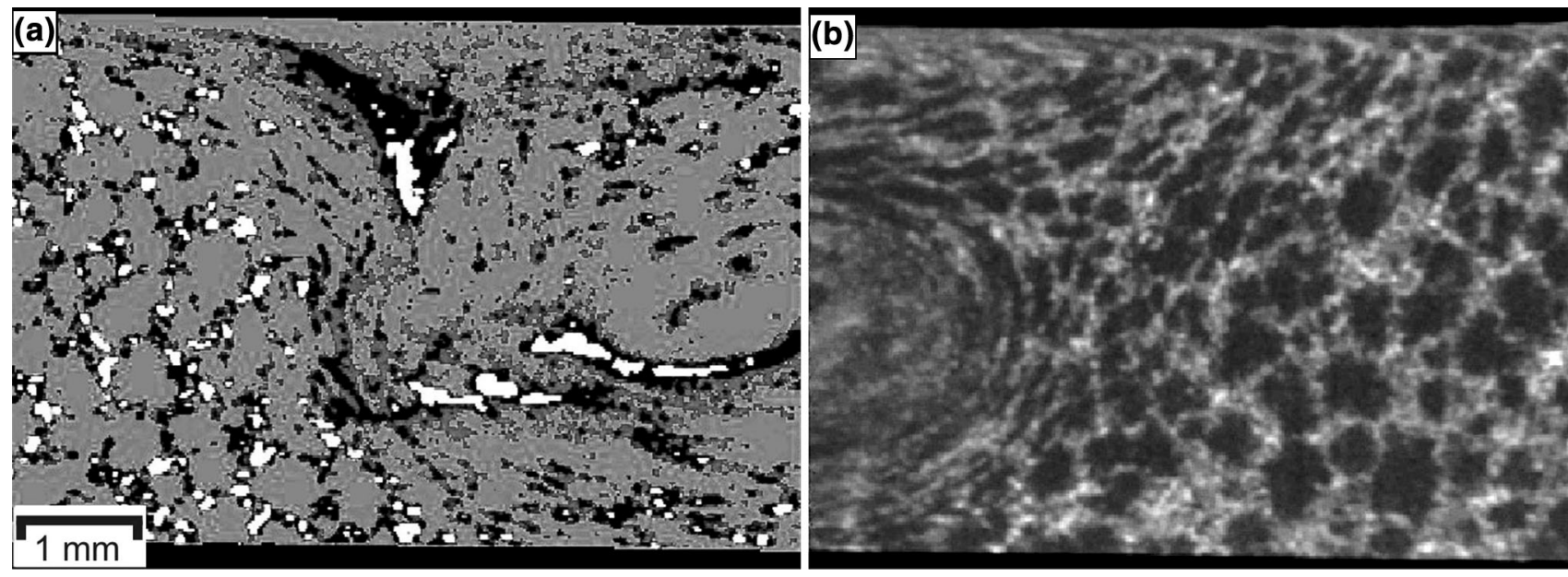

Fig. 5 (a) The result of segmentation of x-ray microstructure on the advancing side: white areas-Al-Fe-Mn-Si phase, black and dark gray areas - $\mathrm{SiC}$ and eutectic $\mathrm{Si}$, another areas - matrix of composite rich in Al. (b) Two-dimensional x-ray cross-section of microstructure-retreating side

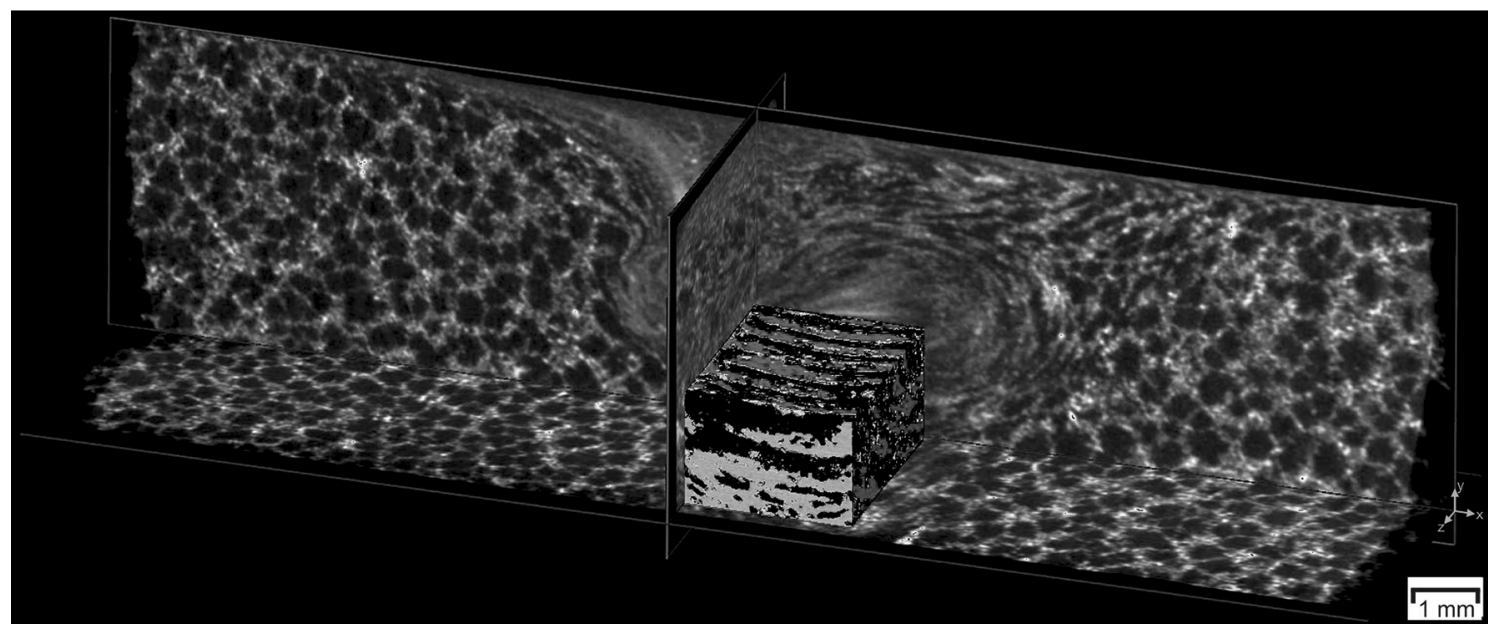

Fig. 6 Three-dimensional model of the weld cross-section of the nugget, located in the plane of two-dimensional cross-section

particles of eutectic Si are. Measurement was made on images of the weld nugget center. The fineness of the particles is related to the intensity of material flow, which is different within the different areas of the weld. The effect of varying in the intensity of the material flow is clearly visible in the XMT imageFig. 4. However, one can possible to identify the conglomerates of particles and segregation (as mentioned earlier), to specify the layout of the microstructure at each site area of operation of the tool. It is possible to try to determine the direction of flow of the material in the last phase before the formation of the microstructure in the final appearance.

The system components of the microstructure (recognizable using $\mathrm{x}$-ray) indicate that microstructural changes are cyclical due to the rotational movement of the FSW tool and simultaneous linear motion. This is shown in $3 \mathrm{D}$ reconstruction-Fig. 6. Lighter bands have the shape of spherical layers. It proves that (as expected) the material, which is behind the pin, is moved downwards (movement forced due to the presence of the thread on the surface of the pin), and in the direction of linear movement of the tool. Simultaneously, the material flows around the tool, as a result of rotation movement of the tool. The advantage of microtomography analysis over conventional (metallurgical) examination of cross-sections of the welds, it can be concluded, that the heterogeneity of this area is essentially constituted by the layered structure, presumably resulting from the shape of the mandrel, i.e., the threaded pin. This observation indicates the lack of intense mixing of the material in this area. This in turn shows that the transport of the material (flow) is done by streams of material flowing. And also the material flow in the lower areas has another important feature - a high degree of plastic deformation. It causes that in aluminum alloys, the nugget area is dynamically recrystallized (Ref 30), and an average grain size reaches a few to several microns. This area may have a layered structure (in crosssection), which in the subject literature was called "onion rings" (Ref 31), which occur at a different layer arrangement (the layer presents in Fig. 4). The microstructure depends on the parameters of the process $(\operatorname{Ref} 32,33)$ and the tool used. It is also dependent on the type of alloy that is processed or sealed. Regardless of the process conditions, material flow in 
the area of the weld nugget (Fig. 5) causes a considerable fragmentation of the microstructure. The observations, however, a limited scope of mixing of the material in an area above of the weld nugget may confirmed, segregation persists although its shape has changed as a result of the material flow.

As it was shown, using XMT to study this type of aluminum alloy composite reinforced by $\mathrm{SiC}$ phase can be very useful. It facilitates a description of macro and microstructure of the tested object. Along with the methods permitting the identification of the chemical composition of SEM-EDS and SEMWDS or the identification and determination of particle size distribution of SEM-EBSD, the microtomography enables to deliver a complex view of the object. The main advantage of $\mathrm{XMT}$ is $3 \mathrm{D}$ imaging since it is a non-destructive testing method of the internal structure of the object.

\section{Conclusions}

1. The XMT images allowed to identify areas of different material density as a result of segregation of chemical composition. This enabled to illustrate both the heterogeneity in the material which was not subjected to plastic deformation, as well as in the areas that were subjected to the FSP process.

2. The microstructure of the area subjected to the FSP process with the specific parameters used, (seen in the XMT images) shows a classic asymmetry and macroscopic inhomogeneity. On the strip on the advancing side, where the microstructure is altered by reinforcement, there is a local segregation at the interface between the material flow directions.

3. Three-dimensional reconstruction is able to show the layered structure of the area near the weld nugget. The structure stems from the way of material flow. The area of the weld nugget has a typically oriented microstructure similar to FSW welds. This area contains significantly fragmented microstructure.

4. On the accepted level of XMT analysis, it was unsuccessful to determine the particle size distribution of $\mathrm{SiC}$, but these particles conglomerate to a limited extent can be recognized.

\section{Acknowledgments}

Anna Wójcicka is a beneficiary of Silesian Cooperation: Innovations For Efficient Development (SWIDER). Project realized within Human Capital Operational Programme, Priority VIII: Regional human resources for economy, 8.2 Transfer of knowledge, Sub-measure 8.2.1 Support to cooperation of scientific environment and enterprises. Project partially funded from European Union Project based on European Social Funds; University of Silesia, Katowice, Poland. FSW process was done in the Institute of Welding in Gliwice, Poland by Dr. Eng. Adam Pietras. Instrumentation (SEM, light microscopy) co-financed by the European Regional Development Fund under the Infrastructure and Environment Programme: "For the Development of the Infrastructure and environment".

\section{Open Access}

This article is distributed under the terms of the Creative Commons Attribution License which permits any use, distribution, and reproduction in any medium, provided the original author(s) and the source are credited.

\section{References}

1. W.M. Thomas, E.D. Nicholas, J.C. Needham, M.G. Murch, P. Templesmith, and C.J. Dawes, Friction Stir Butt Welding. The Welding Institute (TWI), PCT World Patent Application WO 93/10935, 1992, Filed: Nov 27

2. M. Weglowski, A. Pietras, and A. Weglowska, Effect of Welding Parameters on Mechanical and Microstructural Properties of Al 2024 Joints Produced by Friction Stir Welding, J. Kones Powertrain Transp., 2009, 19, p 523-532

3. A. Kula, L. Blaz, and M. Sugamata, Microstructure and Mechanical Properties of Rapidly Solidified Al-Fe-Ni-Mg Alloys, Mater. Sci. Forum, 2011, 675, p 165-170

4. M. Weglowski and A. Pietras, Friction Stir Processing-Analysis of the Process, Arch. Metallurg. Mater, 2011, 56(3), p 779-788

5. R. Fu, Z. Sun, R. Sun, Y. Li, H. Liu, and L. Liu, Improvement of Weld Temperature Distribution and Mechanical Properties of 7050 Aluminum Alloy Butt Joints by Submerged Friction Stir Welding, Mater. Des., 2011, 32, p 4825-4831

6. Y. Hwang, Z. Kang, Y. Chiou, and H. Hsu, Experimental Study on Temperature Distributions Within the Workpiece During Friction Stir Welding of Aluminum Alloys, Int. J. Mach. Tools Manuf., 2008, 48, p 778-787

7. Y.C. Chen, J.C. Feng, and H.J. Liu, Precipitate Evolution in Friction Stir Welding of 2219-T6 Aluminum Alloys, Mater. Charact., 2009, 60, p 476-481

8. A. Kula, L. Blaz, M. Sugamata, and J. Kaneko, Effect of Annealing Temperature on the Structure and Mechanical Properties of Mechanically Alloyed AlMg-Nb2O5 and AlMg-ZrSi2 Composites, J. Microsc., 2010, 237, p 421-426

9. D.J. Loyd, Particle Reinforced Aluminium and Magnesium Matrix Composites, Int. Mater. Rev., 1994, 39(1), p 1-24

10. P. K. Rohagi, and R. Astahana, Caste Reinforced Metal Composites, S.G. Fishman, A.K. Dhingra

11. Froyen L., In Situ Processing of MMCs End of the Wetting Problems? Transactions of Japan Welding Research Institute, Special Issue, Proceedings of HTC-2000, Vol 30, 2001

12. R. Stuart Stock, Microcomputed Tomography. Methodology and Applications, CRC Press, Boca Raton, 2008

13. J.C. Elliott, and S.D. Dover, x-ray Microtomography, J. Microsc. 1982, 126/Pt 2 (211-3), 22-2720

14. P.B. Flannery, H.W. Deckman, W.G. Roberge, and K.I. D'amico, Three-Dimensional x-ray Microtomography, Science, 1987, 237(4821), p 1439-1444

15. W.S. Haddad, I. McNulty, J.E. Trebes, E.H. Anderson, R.A. Levesque, and L. Yang, Ultrahigh Resolution x-ray Tomography, Science, 1994, 266(5188), p 1213-1215

16. E. Perilli, M. Baleani, C. Öhman, R. Fognani, F. Baruffaldi, and M. Viceconti, Dependence of Mechanical Compressive Strength on Local Variations in Microarchitecture in Cancellous Bone of Proximal Human Femur, J. Biomech., 2008, 41, p 438-446

17. S. Mantini and M. Ripani, Modern Morphometry: New Perspectives in Physical Anthropology, New Biotechnol., 2009, 25(5), p 325-330

18. B. Błażejowski, M. Binkowski, M.A. Bitner, and P. Gieszcz, X-ray Microtomography (XMT) of Fossil Brachiopod Shell Interiors for Taxonomy, Acta Palaeontol. Pol., 2011, 56(2), p 427-428

19. R. Moreno-Atanasio, R.A. William, and X. Jia, Combining x-ray Microtomography with Computer Simulation for Analysis of Granular and Porous Materials, Particuology, 2010, 8, p 81-99

20. D. Bernarda, Ø. Nielsenb, L. Salvoc, and P. Cloetensd, Permeability Assessment by 3D Interdendritic Flow Simulations on Microtomography Mappings of Al-Cu Alloys, Mater. Sci. Eng. A, 2005, 392(1-2), p 112-120

21. A. Kula, L. Blaz, and M. Sugamata, Structural and Mechanical Features of Rapidly Solidified Al-2Fe-Ni-5Mg Alloy, Solid State Phenom., 2012, 186, p 279-282 
22. T. Rougelot, N. Burlion, D. Bernard, and F. Skoczylas, About Microcracking Due to Leaching in Cementitious Composites: x-ray Microtomography Description and Numerical Approach, Cem. Concrete Res., 2010, 40(2), p 271-283

23. L.A. Feldkamp, L.C. Davis, and J.W. Kress, Practical Cone-Beam Algorithm, J. Opt. Soc. Am. A, 1984, 1(6), p 612-619

24. K. Mroczka, J. Dutkiewicz, and A. Pietras, Microstructure of Friction Stir Welded Joints of 2017a Aluminum Alloy Sheets, J. Microsc., 2010, 237(3), p 521-525

25. L. Karthikeyan, V.S. Senthilkumar, V. Balasubramanian, and S. Natarajan, Mechanical Property and Microstructural Changes During Friction Stir Processing of Cast Aluminum 2285 Alloy, Mater. Des., 2009, 30, p 2237-2242

26. G. Mrówka-Nowotnik, J. Sieniawski, and M. Wierzbińska, Intermetallic Phase Particles in 6082 Aluminium Alloy, Arch. Mater. Sci. Eng., 2007, 28(2), p 69-76

27. E. Bousquet, A. Poulon-Quintin, M. Puiggali, O. Devos, and M Touzet, Relationship Between Microstructure, Microhardness and
Corrosion Sensitivity of an AA 2024-T3 Friction Stir Welded Joint, Corrosion Sci., 2011, 53, p 3026-3034

28. H.G. Salem, Friction Stir Weld Evolution of Dynamically Recrystallized AA 2095 Weldments, Scripta Mater, 2003, 49, p 1103-1110

29. K. S. Kumar, G. Bao, Intermetallic-matrix composites: an overview, Composites Science and Technology, 52, 1994

30. C.H. Cáceres, M.B. Djurdjevic, T.J. Stockwell, and J.H. Sokolowski, The Effect of cu Content on the Level of Microporosity in Al-Si-CuMg Casting Alloys, Scripta Mater., 1999, 5, p 631-637

31. J. Adamowski and M. Szkodo, Friction Stir Welds (FSW) of Aluminium Alloy AW6082-T6, J. Achiev. Mater. Manuf. Eng., 2007, 20(1-2), p 403-406

32. K.A.A. Hassan, A.F. Norman, D.A. Price, and P.B. Prangnell, Stability of Nugget Zone Grain Structure in High Strength Al-Alloy Friction Stir Welds During Solution Treatments, Acta Mater, 2003, 51, p 1923-1936

33. C. Hamilton, A. Sommers, and S. Dymek, A Thermal Model of Friction Stir Welding Applied to Sc-Modified Al- $\mathrm{Zn}-\mathrm{Mg}-\mathrm{Cu}$ Alloy Extrusions, Int. J. Mach. Tools Manuf., 2009, 49(3-4), p 230-231 